\title{
Why Do Adaptable People Feel Less Insecure? Indirect Effects of Career Adaptability on Job and Career Insecurity via Two Types of Perceived Marketability
}

Journal of Career Assessment 2016, Vol. 24(2) 289-306 (C) The Author(s) 2015 Reprints and permission: sagepub.com/journalsPermissions.nav DOI: $10.1177 / 10690727 / 5580415$ jca.sagepub.com

(SAGE

\author{
Daniel Spurk', Simone Kauffeld ${ }^{2}$, Annika L. Meinecke², \\ and Katharina Ebner ${ }^{3}$
}

\begin{abstract}
The aim of the present study was to analyze if and how career adaptability reduces different types of insecurity. More specifically, we argue in a theoretical model at the intersection of career and organizational research that perceived internal and external marketability serve as connecting variables in the link between career adaptability and job and career insecurity. We tested our assumptions by means of multiple indirect effects path analyses across two measurement points (6-month time span) with data from I42 university researchers working in the science, technology, engineering, mathematics (STEM) fields. The results showed that career adaptability was positively related to perceived internal and external marketability, which both subsequently were negatively associated with job and career insecurity. We draw theoretical implications for career research in intra- and extraorganizational settings and discuss practical implications for fostering secure employment.
\end{abstract}

\section{Keywords}

career adaptability, job insecurity, career insecurity, internal and external marketability

Over the past two decades, labor market regulations, economic and organizational changes, global business competition, and technological advancements have shaped a career and work environment

\footnotetext{
' Department of Industrial and Organizational Psychology, Universität Bern, Bern, Switzerland

${ }^{2}$ Technische Universität Braunschweig, Braunschweig, Germany

${ }^{3}$ Friedrich-Alexander Universität Erlangen-Nürnberg, Germany
}

Corresponding Author:

Daniel Spurk, Department of Industrial and Organizational Psychology, Universität Bern, Fabrikstrasse 8, Bern 30I2, Switzerland.

Email: daniel.spurk@psy.unibe.ch 


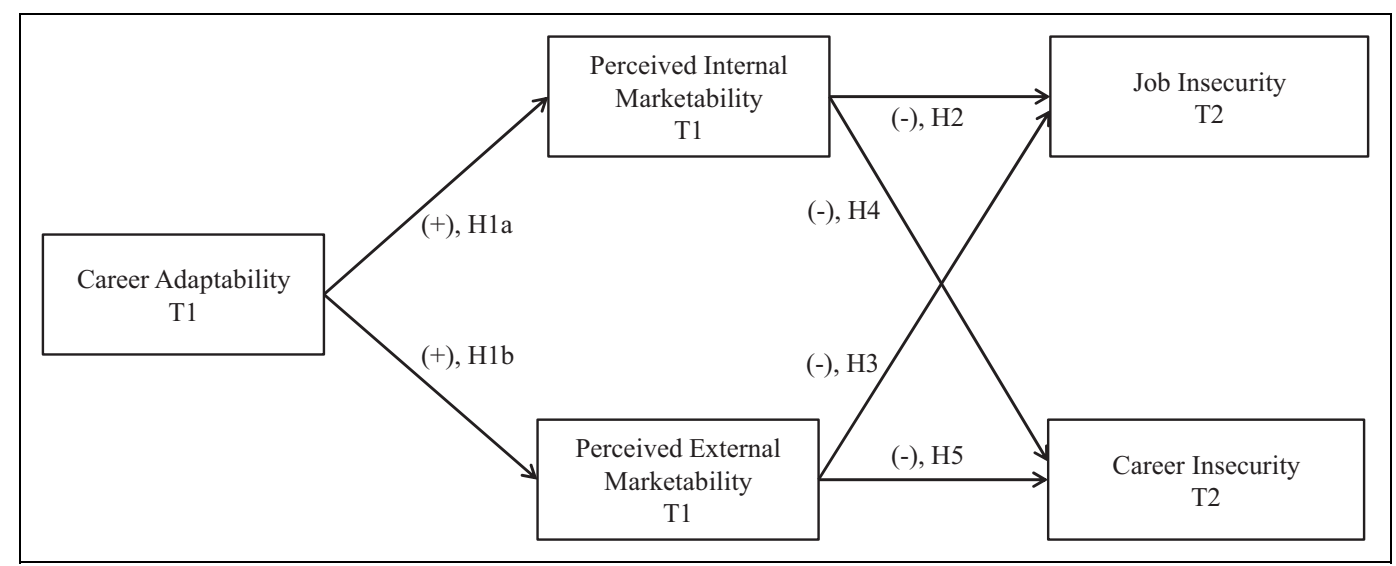

Figure I. Theoretical indirect effects model from career adaptability on job insecurity and career insecurity via perceived internal marketability (within organization) and perceived external marketability (outside organization).

with high levels of insecurity (Cheng \& Chan, 2008; Colakoglu, 2011; De Witte, 1999). Job insecurity is an important and frequently studied insecurity variable and refers to the overall concern about the continued existence of one's job (De Cuyper, Raeder, van der Heijden, \& Wittekind, 2012; De Witte, 1999; Sverke \& Hellgren, 2002). Moreover, as lifetime employment with one single employer is declining and employees frequently rotate between different organizations and even career fields (Arthur \& Rousseau, 1996; Hall, 2002), career insecurity has become an understudied variable of growing interest (Colakoglu, 2011; Höge, Brucculeri, \& Iwanowa, 2012; TrevorRoberts, 2006). Career insecurity can be defined as a feeling of being unable to attain continuous employment (Colakoglu, 2011) and thus of being unable to reach personal goals within one's entire career (Höge et al., 2012).

The aim of the present study was to analyze antecedents of job and career insecurity to provide a better understanding of which factors are affecting these concepts. Therefore, we theoretically develop and empirically test an indirect effect model that explains why career adaptability is linked to job and career insecurity. Specifically, we explore whether career adaptability is positively related to perceived internal and external marketability and whether both marketability types, in turn, are negatively related to job and career insecurity (see Figure 1). Other authors have stated that employability-related perceptions of individuals are consequences of human capital variables (Eby, Butts, \& Lockwood, 2003; Wittekind, Raeder, \& Grote, 2010), like career adaptability, and at the same time are antecedents of insecurity judgments (e.g., De Cuyper et al., 2012; Keim, Landis, Pierce, \& Earnest, 2014; Sverke \& Hellgren, 2002). Hence, the employability-related concept of perceived marketability conceptually fits well as a connecting variable. Perceived internal marketability describes the self-assessed value and employability of individuals for their current organization. By contrast, perceived external marketability represents the belief of individuals in their value and employability across organizational boundaries (Eby et al., 2003; Spurk, Volmer, Hagmaier, \& Kauffeld, 2013).

By testing the assumed model, we consider an important career competence, namely, career adaptability (Hall, 2002), to explain positive work and career outcomes in terms of reduced insecurity. Furthermore, our research model allows to analyze whether different marketability types (i.e., internal marketability and external marketability) are equally or differentially important for predicting job and career insecurity. In sum, past studies mostly focused on job insecurity solely and did not examine career insecurity. We integrate both insecurity types in one comprehensive model. Moreover, past research did not differentiate between different types of employability when predicting 
job insecurity and this study sets out to fill this research gap (Cuyper, Raeder, van der Heijden, \& Wittekind, 2012; Sverke \& Hellgren, 2002).

To empirically test our research model, we analyzed a working sample of academic researchers from the science, technology, engineering, mathematics (STEM) fields in their early career stages (employed in German universities). Although this sample is very specific with respect to education, skills, and work demands, it nonetheless represents a sample very suitable for the here analyzed research question. In Germany, research associates in early career stages qualify as faculty members and hold regular positions within their departments. The participants in our study mostly engaged in teaching and research activities. Research associates usually are temporally employed with the possibility to receive extended working contracts. Furthermore, an early career stage in this academic field is usually associated with job or responsibility changes, as well as high demands for job, organizational, and career adaptability (cf. Baruch \& Hall, 2004).

\section{Career Adaptability: Definition and the Relations to Perceived Marketability}

Super and his colleagues (Super \& Kidd, 1979; Super \& Knasel, 1979) introduced the term "career adaptability" to conceptualize how adults adjust to the challenges of a changing world of work. In the past years, different structural conceptualizations and operationalizations of career adaptability have been developed and implemented (one-factor structure: Rottinghaus, Day, \& Borgen, 2005, four-factor structure: Savickas \& Porfeli, 2012, and five-factor structure: Nota, Ginevra, \& Soresi, 2012). However, at the core, all conceptualizations deal with adjustments to changes in one's career and to work. Moreover, in general, the theoretical rationales of why and how career adaptability may affect work outcomes are principally comparable and are based on the work of Super and colleagues and were recently extended by Rottinghaus, Day, and Borgen (2005) and by Savickas and Porfeli (2012). We decided to rely on a one-dimensional global career adaptability conceptualization because it captures the core essence of the construct that should affect a broad range of outcome variables (cf. Rottinghaus et al., 2005). Furthermore, we did not focus on different relations between different career adaptability components and their specific outcomes. Hence, in this study career adaptability is defined as the "capacity to cope with and capitalize on change in the future, level of comfort with new work responsibilities, and ability to recover when unforeseen events alter career plans" (Rottinghaus et al., 2005, p. 11).

We argue that career adaptability is positively related to both internal and external marketability for at least two reasons. First, protean career theory (Hall, 2002) describes career adaptability as a major meta-competence, which is responsible for adaptable behavior across career-related work and nonwork domains. According to Hall (2002), adaptable behaviors are expressed, for example, by planning activities, performing effectively in well- and ill-defined situations, responding differently to varying environments, and seeking new challenges in unexplored territory. These behaviors should be positively related to internal and external marketability. Additionally, one core component of career adaptability is the individual's skill to cope with changing or destructive career stimuli (e.g., Rottinghaus et al., 2005; Savickas \& Porfeli, 2012; Spurk \& Volmer, 2013). Nowadays, these stimuli occur more rapidly and unpredictably (Hall, 2002; Rottinghaus et al., 2005), and as such, career adaptability is crucial for handling an individuals' value-related self-evaluation (e.g., marketability). For example, career relevant within-organizational stimuli that individuals have to adapt to might be downsizing, changing organizational structures, changing work tasks, high strains, rotating colleagues or supervisors, or changing work-roles. Career relevant outside-organizational stimuli might be changes in the economic environment, job market regulations, opportunities within other employers, and work-family issues. As adaptable individuals cope more effectively with such stimuli, they should perceive themselves as more marketable within and outside the actual employer. 
Second, latest research on career adaptability (Savickas \& Porfeli, 2012) stated that career adaptability can be seen as self-regulation strengths or capacities that a person may draw upon to solve career-related tasks. Therefore, career adaptability helps solving unfamiliar, complex, and illdefined problems presented by developmental vocational tasks, occupational transitions, and work traumas. Moreover, it is assumed that adaptability resources are not at the core of the individual like personality traits, but they are located at the intersection of person-in-environment. From this perspective, perceived employability is a similarly developing construct as it also refers to the intersection of the person-in-environment (inside and outside organization). Moreover, assumed components of career adaptability (i.e., concern, control, curiosity, and confidence, Savickas \& Porfeli, 2012) are all helpful for building up perceived internal and external marketability. Concern helps individuals to anticipate future career developments. Control enables individuals to take responsibility for their careers and to be persistent meanwhile curiosity is positively related to identity formation and role integration. Finally, confidence should be positively related to perceived marketability because it leads to implemented behaviors that directly affect an individual's selfevaluation.

Empirically, career adaptability is related to other variables that also relate to perceived marketability. For example, Rottinghaus and colleagues (2005) showed that career adaptability is positively related to problem solving confidence, personal control, approach style, risk taking, and job market knowledge (i.e., searching for information across organizational boundaries). Similarly, de Guzman and Choi (2013) found that career adaptability is positively associated with communication, problem solving, and team work. Other research revealed that career adaptability positively relates to work engagement (Maggiori, Johnston, Krings, Massoudi, \& Rossier, 2013), career optimism, career satisfaction, salary, and promotions (Spurk \& Volmer, 2013), and negatively relates to perceived within-person and external-person career barriers (Soresi, Nota, \& Ferrari, 2012). Finally, Duffy (2010) demonstrated that career adaptability is positively associated with sense of control, selfesteem, and social support. Regarding these empirical findings and the theoretical notions from above (Hall, 2002; Rottinghaus et al., 2005), we posit that career adaptability should positively relate to both perceived internal and external marketability.

Hypothesis 1: Career adaptability is positively related to perceived (a) internal and (b) external marketability.

\section{The Relations of Internal and External Marketability With Job Insecurity}

Individuals with high perceived internal marketability think that they perform well in their current job, contribute to organizational success, and hence, maintain continuous employment within their actual organization (De Cuyper et al., 2012; Eby et al., 2003). By contrast, individuals with high perceived external marketability are confident that they could perform well within other organizations and thus could contribute to the success of different organizations within the labor market, and therefore, maintain continuous employment across several organizations (De Cuyper et al., 2012; Eby et al., 2003). A theoretical framework by Sverke and Hellgren (2002) assumed perceived employability as an important subjective antecedent of job insecurity. Furthermore, the underlying rationale for why perceived marketability relates to job insecurity should also be transferable to career insecurity because marketability questions need to be answered at the core of both insecurity judgments and can be explained by human capital theory (Becker, 1993).

Job insecurity received a large amount of attention in past research, and consequentially, has been defined in various ways. "One's expectations about continuity in a job situation" (Davy, Kinicki, \& Scheck, 1997, p. 323) is, for instance, a well-known definition of job insecurity. Generally it can also be regarded as "overall concern about the future existence of the job" (Rosenblatt \& Ruvio, 1996, 
p. 587; see also Cheng \& Chan, 2008). As jobs develop within specific organizations, an individual's perceived value and employment options within the organization (i.e., internal marketability) should reduce job insecurity. This reduction in job insecurity does not only occur due to a more highly perceived probability of extensions of temporary working contracts or re-positioning after organizational changes, but also due to brighter career and advancement opportunities for an individual within inner organizational job markets (e.g., Parker \& Arthur, 2002). Individuals with more highly perceived internal marketability usually have well-developed intraorganizational networks that provide them with such opportunities (Eby et al., 2003). Furthermore, an actual meta-analysis about predictors of job insecurity has shown that organizational communication was negatively, and role ambiguity and role conflict were positively related to job insecurity (Keim et al., 2014). Individuals with high-internal marketability should be better embedded within organizational communication processes and also experience lower levels of role ambiguity and role conflicts.

Hypothesis 2: Perceived internal marketability is negatively related to job insecurity.

A central idea in Human Capital Theory (Becker, 1993) is that workers expect and often negotiate a return on earlier investments. Based on rationales of De Cuyper and colleagues (2012), we argue that workers with higher external marketability have invested more time and resources in the past, for example, in more education, skill development, long work hours, or adaptable behaviors. Now, they are interested in benefiting from these investments. Such benefits need not necessarily be financial incentives, but can also be nonfinancial in nature. Furthermore, in times of rare talents, the skill and attitude profiles of such highly employable workers are in demand in extraorganizational job markets. As a consequence, employers may want to tie these workers to their organization and keep them away from competitors by providing them with opportunities, incentives, and secure jobs. Against the backdrop of more unstable careers, secure jobs are experienced as a trade-off of the organization for past investments of the employee.

Hypothesis 3: Perceived external marketability is negatively related to job insecurity.

\section{The Relations of Internal and External Marketability With Career Insecurity}

In contrast to job insecurity, career insecurity is a vastly understudied construct. However, career insecurity is of particular importance in new career environments (Hall, 2002; Höge et al., 2012), especially against the background of increased mobility (Trevor-Roberts, 2006). Colakoglu (2011) stated that individuals experience career insecurity when they feel powerless to maintain continuous employment in their careers. This approach seems to be relatively closely related to perceived external marketability. Extending this view, Höge, Brucculeri, and Iwanowa (2012) noted that career insecurity is an individual's insecurity about the attainment of mid- to long-term career goals. From this perspective, career insecurity is an expectation of insecure careers that additionally does not meet the fulfillment of an individual's career goals. Such evaluations of career insecurity are not necessarily based solely on within organizational jobs, but can cross organizational boundaries. Both perceived internal and external marketability might be related to career insecurity as career goals may be fulfilled within both intra- and extraorganizational job markets, respectively.

Internal and external marketability are typically associated with social networks that may play a major role in reducing career insecurity, as contacts within and outside the organization provide new employment contracts, other career options, upward mobility, or new responsibilities that provide secure career goal fulfillment (DeFillippi \& Arthur, 1994; Eby et al., 2003; Wolff \& Moser, 2009). Internal and external marketability are also associated with career identity, which plays a major role for setting clear and attainable mid- to long-term career goals (DeFillippi \& Arthur, 1994; Eby et al., 2003; Hall, 2002). This should reduce career insecurity. Persons with high internal 
and external marketability perceptions usually have higher job- and career-related skills (DeFillippi \& Arthur, 1994; Eby et al., 2003) that should reduce career insecurity because of a high demand for such skills within the organization and the labor market. Such high-demand positions, in turn, can be used to negotiate job conditions that allow mid- to long-term career goal fulfillment. In a study by Höge and colleagues (2012), conflicts between work and private goals increased career insecurity. Internal and external marketability might help to solve these goal conflicts because it helps to occupy positions with better work-life goal fit. In sum, again applying the human capital theory (Becker, 1993), high career security can be interpreted as nonfinancial payback by the organization or the labor market to earlier work and career-related investments of an individual.

Hypothesis 4: Perceived internal marketability is negatively related to career insecurity.

Hypothesis 5: Perceived external marketability is negatively related to career insecurity.

In sum, based on the theoretical notions leading to Hypotheses 1-5, we derive the following indirect effects hypotheses:

Hypothesis 6: There will be a negative indirect relation of career adaptability with job insecurity via perceived internal marketability.

Hypothesis 7: There will be a negative indirect relation of career adaptability with job insecurity via perceived external marketability.

Hypothesis 8: There will be a negative indirect relation of career adaptability with career insecurity via perceived internal marketability.

Hypothesis 9: There will be a negative indirect relation of career adaptability with career insecurity via perceived external marketability.

\section{Method}

\section{Procedure and Participants}

Data were collected as part of a German research program focusing on the career support of academic scientists in an early career stage (i.e., research associates). All participants took part in our study by accessing an online survey at two points of measurement. Participants were first surveyed in the summer term of the academic year (Time 1 or T1) and again half a year later in the winter term of the academic year (Time 2 or T2). We recruited participants via (a) promotional presentations held in their respective university departments or (b) mailing lists. We sent out invitations to complete the online survey after the promotional presentations. Of these potential participants, $75 \%$ participated in our study, which made up $23 \%$ of our overall sample. The remaining participants $(77 \%)$ were recruited via mailing lists. It was not possible to obtain response rates for this subgroup. Comparing T1 and T2, we had $49.3 \%$ dropout, which is comparable to previous longitudinal studies applying a similar research strategy (e.g., Bott \& Duffy, 2014; Hirschi \& Herrmann, 2012). More details on the state of the art treatment of longitudinal missing data used here (i.e., full information maximum likelihood) are explained below in the Methods section.

The sample comprised a total of 142 research associates. Of these participants, $46 \%$ were male and $54 \%$ were female. Participants' average age was 29.13 years $(S D=3.36)$. Organizational tenure was distributed across the following categories: 0-1 years $(32.5 \%), 2-3$ years $(39 \%), 4-5$ years (16.3\%), and more than 5 years (12.2\%). Among the participants, $58.4 \%$ held a full-time position and $41.6 \%$ held a part-time position. On average, participants had attended university for 5.76 years $(S D=1.73)$ prior to graduation, and their mean final university grade was $1.59(S D=.39)$. All 
participants held a master degree. German universities use a grading system ranging from 1 (very good) to 4 (sufficient). All participants worked within the so-called MINT fields, which is the German equivalent for STEM fields: $2.4 \%$ mathematics, $12.7 \%$ informatics/computer science, $34.9 \%$ natural sciences, and $50 \%$ technology/engineering.

With regard to dropout, 70 complete data records were available for longitudinal analyses (72 dropouts). We compared the data we obtained from persons at both times of measurements with data from persons who did not participate at T2. Testing for significant differences between those groups on the $5 \%$ level revealed no significant group differences on relevant variables (e.g., age, organizational tenure, contract type, and final university grade). However, the groups differed regarding the gender distribution so that slightly more men than women dropped out from T1 to T2.

\section{Measures}

We measured all study variables by means of standardized questionnaires using a 6-point rating scale each $(1=$ not at all to $6=$ very much $)$. Demographics, career adaptability, and perceived marketability were measured at T1. Job insecurity and career insecurity were measured at T2. We did not assess all variables at all times because we were mainly interested in absolute levels and not changes in the study variables. Furthermore, past research on insecurity variables revealed a relatively high stability of job insecurity across time spans of 12-18 months (Mauno, Leskinen, \& Kinnunen, 2001), which is even longer than the here assessed time span. The scales' internal consistency was measured using Cronbach's $\alpha$. We compared values between those participants who participated at both times of measurement and those who dropped out of the study and found no significant differences.

Career adaptability. We measured career adaptability using a validated German version of the Career Future Inventory (CFI, Rottinghaus et al., 2005; Spurk \& Volmer, 2013 for the German version). The scale's validity was demonstrated extensively concerning, for example, factor structure and convergent validity. Using this scale, career adaptability shows a one-dimensional factor structure and correlates in expected ways with personality, career decision making, and occupational confidence. The German version of the CFI was translated and validated within a sample of employed adults and was recently also applied in young working adult's samples within the academic context (e.g., Spurk, Kauffeld, Barthauer, \& Heinemann, 2015). The German CFI possesses construct as well as criterion-related validity (e.g., correlations with objective and subjective career success; Spurk \& Volmer, 2013). Career adaptability was measured by 11 items. Sample items were "I can adapt to change in my career plans" and "I will adjust easily to shifting demands at work." Cronbach's $\alpha$ reached a value of $\alpha=.86$.

Perceived marketability. We measured perceived marketability using a German version of a scale reported by Eby, Butts, and Lockwood (2003) who also demonstrated the measures' construct validity. For instance, perceived marketability was positively correlated with internal and external networking, with career-related competencies, and with perceived career success. Perceived internal marketability was measured by 3 items ("My company views me as an asset to the organization," "Given my skills and experience, the company that I work for views me as a value-added resource," "There are many opportunities available for me in my company"; Cronbach's $\alpha=.84$ ). By contrast, perceived external marketability describes the perceived value of the employed individual for other organizations and was again measured by 3 items ("I could easily obtain a comparable job with another employer," "There are many jobs available for me given my skills and experience," and "Given my skills and experience, other organizations view find me as a value-added resource"; Cronbach's $\alpha=.92$ ). For both subscales, Cronbach's $\alpha$ yielded similar values compared to the English version thus demonstrating the subscales' internal consistency. A principal component 
exploratory factor analysis with promax rotation revealed an expected two-factorial solution (items load as expected on one internal and one external factor).

Job insecurity. We assessed job insecurity with a slightly adapted German scale used by Staufenbiel and König (2010). The scale consisted of 3 items representing an individual's cognitive evaluation of his or her individual job insecurity. Regarding its validity, for instance, the scale negatively relates to task performance and positively to an individual's turnover intention. Sample items are "My job is secure (recoded)" and "In my opinion, I will keep my job in the near future." Cronbach's $\alpha$ was good with .90 thus corresponding to internal consistency values reported in previous publications using the scale (e.g., König, Debus, Häusler, Lendenmann, \& Kleinmann, 2010).

Career insecurity. Career insecurity was measured with a one-dimensional German 4-item scale reported by Höge et al. (2012). The items were: "I am not sure whether I shall achieve my career aims," "I consider my professional development to be secure (recoded)," "It is difficult for me to plan my professional future," and "I often wonder how my career will develop." The scale was developed to measure an individual's insecurity evaluation regarding the attainment of one's career aims. In the initial validation study, the scale was tested in a similar sample as in our study (i.e., researchers working in Universities in Austria, Germany, and Switzerland) and was positively related to job insecurity and work-family conflict and negatively related to protean career orientations and well-being. Compared to the cited previous studies, in the present sample, Cronbach's $\alpha$ was slightly lower reaching a value of .69. However, as the items of the scale tap slightly different insecurity contents, the internal consistency can be regarded as acceptable for a 4-item scale (Clark \& Watson, 1995).

Control variables. We controlled for age, gender, contract type $(0=$ part-time, $1=$ full-time $)$, and final grade of university studies (i.e., the master's degree or diploma) because these variables are either related to perceived marketability perceptions or job and career insecurity (Colakoglu, 2011; Eby et al., 2003; Höge et al., 2012; Sverke \& Hellgren, 2002). Moreover, we controlled for research field to account for our specific sample characteristics. We combined the research fields of mathematics, computer science, and natural sciences into one cluster (coded 0; Technology/Engineering coded 1) to obtain balanced clusters.

\section{Analytical Procedure and Missing Data Treatment}

In order to examine the assumption that career adaptability positively affects perceived marketability and the assumption that perceived marketability (internal and external) links career adaptability with job insecurity and career insecurity, a multiple regression path-model was tested (Kline, 2005; using Mplus 7.1: L. K. Muthén \& Muthén, 1998-2012). The model was computed taking into account the two points of measurement of our study: the theoretical model (see Figure 1) consists of one independent variable (career adaptability) and two endogenous connecting variables (internal marketability and external marketability), all measured at $\mathrm{T} 1$. The dependent variables (job insecurity and career insecurity) were measured at $\mathrm{T} 2$.

All path coefficients - both direct and indirect - were estimated simultaneously while controlling for age, gender, contract type, final grade of university studies, and research field. All control variables were modeled as paths on perceived marketability and on all dependent variables in the model (Kline, 2005). We allowed for residual covariance among our dependent variables (i.e., job insecurity and career insecurity) because they are assumed to be related constructs. Moreover, we allowed correlations beyond the postulated paths (i.e., we allowed internal marketability and external marketability to correlate). Exogenous variables (controls and career adaptability) were allowed to correlate as a standard setting in path analyses (L. K. Muthén \& Muthén, 1998-2012). 
Table I. Means, Standard Deviations, Reliabilities, and Correlations Among Study Variables.

\begin{tabular}{lcccccccc}
\hline & $M$ & $S D$ & $\alpha$ & 1 & 2 & 3 & 4 & 5 \\
\hline I. Career adaptability $^{\mathrm{a}}$ & 4.63 & 0.56 & .86 & - & & & \\
2. Perceived internal marketability $^{\mathrm{a}}$ & 4.20 & 0.91 & .84 & $.49^{* * *}$ & - & & \\
3. Perceived external marketability $^{\mathrm{b}}$ & 4.30 & 1.08 & .92 & $.49^{* * *}$ & $.50^{* * *}$ & - & \\
4. Job insecurity $^{\mathrm{b}}$ & 3.08 & 1.45 & .90 & $-.41^{* * *}$ & $-.46^{* * *}$ & $-.58^{* * * *}$ & - & \\
5. Career insecurity $^{\mathrm{b}}$ & 3.43 & 0.89 & .69 & $-.38^{* * *}$ & $-.35^{* * *}$ & $-.38^{* * *}$ & $.50^{* * *}$ & - \\
\hline
\end{tabular}

Note. $\alpha=$ Cronbach's $\alpha$; Pearson's correlations based on $\mathrm{TI}^{\mathrm{a}}$ and $\mathrm{T}^{\mathrm{b}}$-measurements; all constructs measured on a scale ranging from $I$ to 6 .

$* * * p<.001$.

Path analyses were conducted using the maximum likelihood estimator and were processed as full information maximum likelihood estimation (FIML) in order to consider missing data in the estimations. FIML estimations are based on less restrictive assumptions regarding missing values (missing at random) compared to other procedures, such as listwise deletion (Enders \& Bandalos, 2001). FIML estimations are even recommended for missing data proportions of $25-50 \%$ (Enders \& Bandalos, 2001). Additionally, we compared the model results using FIML estimation with results using listwise deletion and found that both approaches yielded highly similar results, thus supporting the decision to run analyses as FIML estimations.

Finally, we calculated specific standardized indirect effects as assumed in the multiple indirect effects model with the standard setting within Mplus. The advantage of this approach is that both direct and indirect effects are calculated simultaneously rather than via several steps (Preacher \& Hayes, 2008). Specific indirect effects are basically calculated as a product term of the two standardized regression path coefficients between the independent variable and indirect variable on one hand, and between the indirect variable and dependent variable on the other hand (Preacher \& Hayes, 2008). Full mediation is indicated by significant indirect effects and nonsignificant direct effects between the independent variable and dependent variable. Partial mediation is indicated by both significant direct and indirect effects (Kline, 2005).

\section{Results}

\section{Preliminary Results and Confirmatory Factor Analyses}

Means, standard deviations, scale reliabilities, and correlations between study variables are presented in Table 1. Career adaptability was negatively correlated with job insecurity $(r=-.41$, $p<.001)$ and career insecurity $(r=-.38, p<.001)$, and positively correlated with internal marketability $(r=.49, p<.001)$ and external marketability $(r=.49, p<.001)$. Internal and external marketability were negatively related to job insecurity $(r=-.46, p<.001$ and $r=-.48, p<.001$, respectively) and career insecurity $(r=-.35, p<.001$ and $r=-.38, p<.001$, respectively). Furthermore, the means of job and career insecurity $(M=3.08, S D=1.45$ and $M=3.43, S D=0.89$, respectively) were above the absolute middle point of the scale (scale range $=1-6$ ); and therefore, comparable to other studies that measured job or career insecurity.

First, we conducted confirmatory factor analyses to test the construct validity of our endogenous connecting variables (i.e., internal marketability and external marketability) and the dependent variables (i.e., job insecurity and career insecurity). We did this because job insecurity, career insecurity, internal marketability, and external marketability are characterized by minor overlaps regarding their content (De Cuyper et al., 2012). First, we tested a four-factor model as suggested in the theoretical model (cf. Figure 1), comprising four single correlated factors. This four-factor model 
yielded a good model fit, $\chi^{2}(58)=97.15, p<.001$, root mean square error of approximation $($ RMSEA $)=.07$, standardized root mean square residua $(\mathrm{SRMR})=.06$, comparative fit index $(\mathrm{CFI})$ $=.95$. Next, we calculated a single-factor model with all items loading on one single g-factor, which resulted in a decrease in model fit, as indicated by a significant decline in $\chi^{2}$ values, $\Delta \chi^{2}(6)=$ $245.35, p<.001$, compared to the four-factor model. Following, we compared two additional theoretically plausible models to our four-factor model in order to show that the construct of marketability is different from the constructs of job and career insecurity: the first model comprised internal marketability, external marketability, and career insecurity as one factor, and job insecurity as a second factor; the second model comprised internal marketability, external marketability, and job insecurity as one factor, and career insecurity as a second factor. The model fits were worse in both alternative two-factor models, $\Delta \chi^{2}(5)=175.05, p<.001$ and $\Delta \chi^{2}(5)=243.43, p<.001$ and $\Delta \chi^{2}(3)=13.42, p<.01$, respectively. Thus, data supported the expected four-factor model, indicating the two-marketability variables and the two-insecurity variables to be distinct from, but interrelated to, each other. Finally, we tested a model where job and career insecurity loaded on one single factor to test for conceptual distinctness between the insecurity variables. Results showed that job and career insecurity were distinct but interrelated constructs.

\section{Hypotheses Testing: Direct Effects}

For hypothesis testing, we conducted path analyses comprising all paths according to our theoretical model including control variables (Figure 1). The results indicated that the theoretical model shows a good fit to the data, $\chi^{2}(2)=2.62, p=.27, \mathrm{RMSEA}=.05, \mathrm{SRMR}=.02, \mathrm{CFI}=.99$. In addition, we compared our theoretical model to a full model that comprised two additional direct paths linking career adaptability to job insecurity and career insecurity, respectively. Results showed that career adaptability was neither directly related to job insecurity nor to career insecurity. This saturated full model showed a higher BIC value in comparison to our theoretical model (full model BIC = 3,167.60; theoretical model BIC $=3,160.34$ ) indicating worse model fit. Thus, we decided on the more parsimonious theoretical model. Standardized path coefficients (significant, including control variables) are presented in Figure 2.

Our first hypothesis concerned the direct effects of career adaptability on perceived internal (Hypothesis 1a) and perceived external marketability (Hypothesis 1b). As predicted, the effect of career adaptability on perceived internal marketability $(\beta=.43, p<.001)$, as well as on perceived external marketability $(\beta=.42, p<.001)$, was significant and positive, thus supporting Hypotheses $1 \mathrm{a}$ and $1 \mathrm{~b}$. The results indicate that adaptable individuals perceive themselves as more marketable within and outside their organization.

Concerning the importance of perceived marketability for explaining job and career insecurity, the path model showed a significant and negative effect of perceived internal marketability on job insecurity $(\beta=-.18, p=.031)$ and a significant and negative effect of perceived external marketability on job insecurity $(\beta=-.44, p<.001)$, thus supporting Hypotheses 2 and 3 . Further, both perceived internal and external marketability were significantly and negatively linked to career insecurity $(\beta=-.24, p=.021 ; \beta=-.33, p=.003$, respectively), supporting Hypotheses 4 and 5 . In the empirical model, perceived internal marketability and perceived external marketability $(r=$ $.26, p=.001)$, as well as job insecurity and career insecurity $(r=.33, p=.003)$, were positively correlated.

\section{Hypotheses Testing: Indirect Effects}

Additionally, we expected that career adaptability would have indirect effects on job insecurity and career insecurity, conveyed by perceived internal and external marketability. Results for indirect 


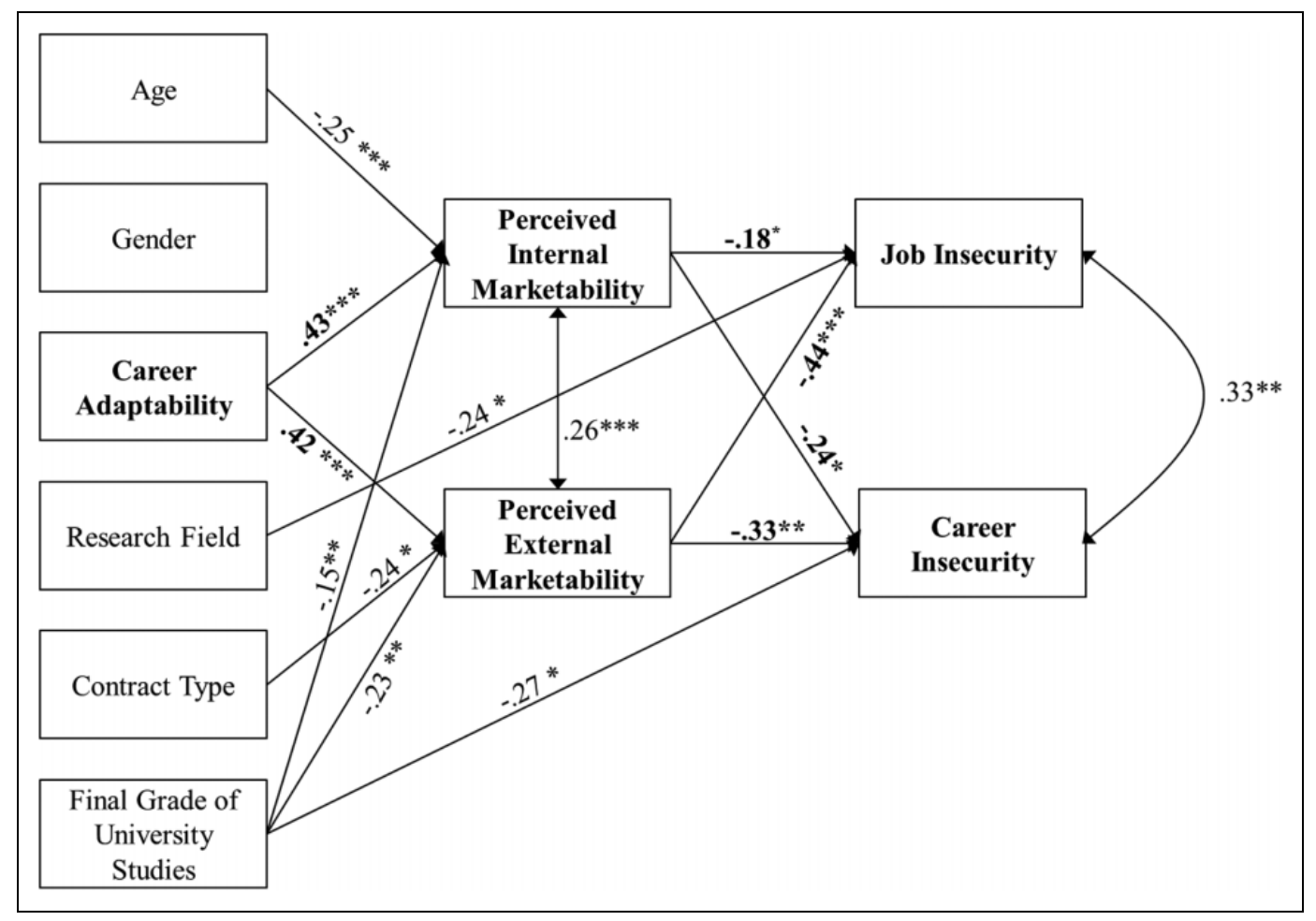

Figure 2. Effects of career adaptability on job insecurity and career insecurity via perceived internal and external marketability.

Note. Path model showing direct effects and estimated correlations; standardized coefficients are depicted; career adaptability, internal marketability, and external marketability measured at Time I (TI), job insecurity and career insecurity measured at Time 2 (T2); all endogenous indirect and dependent variables controlled for age, gender $(0=$ male; I = female), final grade of university studies (ranging from I to 4 , higher values represent lower grades), research field ( $0=$ mathematics/computer sciences/natural sciences; $\mathrm{I}=$ technology/engineering), and contract type $(0=$ part-time, $\mathrm{I}=$ full-time); for clarity only significant paths are shown; coefficients relevant for hypotheses testing are printed in bold; $*_{p}<.05$. ** $*_{p}<.0$ I. $*_{*} * *_{p}<.00$ I.

Table 2. Standardized Indirect Effects of Career Adaptability on Job Insecurity and Career Insecurity via Perceived Internal and External Marketability.

IE on Job Insecurity IE on Career Insecurity

\begin{tabular}{lll}
\hline Career Adaptability $\rightarrow$ Perceived Internal Marketability & $-.08^{*}$ & $-.10^{*}$ \\
Career Adaptability $\rightarrow$ Perceived External Marketability & $-.18^{* * *}$ & $-.14^{* *}$ \\
\hline
\end{tabular}

Note. IE $=$ indirect effect.

$* p<.05 . * * p<.01$. ${ }^{* * *} p<.001$.

effects analyses are presented in Table 2 . The indirect effect of career adaptability on job insecurity via perceived internal marketability was significant and negative $(-.08, p<.05)$, thus supporting Hypothesis 6 . The indirect effect of career adaptability on job insecurity via perceived external marketability was also significant $(-.26, p<.001)$, thus lending support to Hypothesis 7 . Hence, our results show that adaptable individuals are less insecure about their jobs because they perceive themselves as more marketable both within and outside their current organization. 
Our final set of hypotheses predicted a link between career adaptability and career insecurity via perceived internal and external marketability. In line with our hypotheses, we found significant negative indirect effects of career adaptability on career insecurity via both internal marketability and external marketability $(-.10, p<.05 ;-.14, p<.05$, respectively). Hence, adaptable people feel less insecure about their careers because they perceive themselves as more marketable for their actual as well as potential other employers. Because career adaptability was not directly related to job insecurity and career insecurity, internal and external marketability fully mediated all expected relations between career adaptability and the respective insecurity outcomes.

Finally, a closer look at the explained variances in the analyzed model revealed that most variance was explained within job insecurity $\left(R^{2}=.47\right)$, followed by internal and external marketability $\left(R^{2}=.34\right.$ and $R^{2}=.35$, respectively $)$, and career insecurity $\left(R^{2}=.25\right)$.

\section{Additional Tests and Findings}

As an additional test, we analyzed whether the effect sizes of perceived internal and external marketability differ with respect to job and career insecurity. This analysis provides answers to the question of whether internal or external marketability is differentially important for predicting job and career insecurity or not. Therefore, we constrained the paths of internal and external marketability on job insecurity to be equal. This alternative model showed no decline or increase in model fit compared to the baseline model described previously, $\Delta \chi^{2}(1)=1.44, n s$. In a second comparison model, we constrained the paths of internal and external marketability on career insecurity to be equal. Again, this alternative model showed no changes in model fit compared to the baseline model described previously, $\Delta \chi^{2}(1)=-.03$, $n s$. Hence, effect sizes did not vary for either predicting job insecurity or career insecurity.

We also found some significant effects of our control variables. Results showed that final university grade was negatively related external marketability $(\beta=-.23, p=.005)$ as well as to career insecurity $(\beta=-.27, p=.025)$. Because in Germany, higher grades represent lower academic performance, individuals with better grades expressed less external marketability and career insecurity. Furthermore, age was negatively related to internal marketability $(\beta=-.25, p=.001)$. Finally, we found that participants working in the field of technology/engineering experienced lower job insecurity $(\beta=-.24, p=.05)$, and participants with a full-time contract expressed higher external marketability $(\beta=.24, p=.043)$.

\section{Discussion}

The aim of the present study was to analyze whether and how career adaptability is related to job and career insecurity via perceptions of internal and external marketability. The multiple indirect effects analyses delineated the role of both perceived marketability types for explaining effects of career adaptability on job insecurity and career insecurity within a sample of research associates working in the STEM fields at German universities. In sum, the findings support our theoretical model and the related Hypotheses 1-9.

\section{Theoretical Implications}

One implication of our study is that adaptable individuals seem to benefit from their flexibility in several ways. They feel more secure within their current job and their entire career. Previous studies linked career adaptability to well-being, stress, and work behavior (de Guzman \& Choi, 2013; Maggiori et al., 2013; Rottinghaus et al., 2005; Soresi et al., 2012), our study extends this line of research and paints a comprehensive picture of the relevance of career adaptability as a competence 
for within and across organizational careers (Hall, 2002; Savickas \& Porfeli, 2012). Doing so, we added two important organizational and career-related outcome variables to the set of analyzed consequences of career adaptability, namely job insecurity and career insecurity. This is of special importance because nowadays, work, organizational, and career environments are confronted with organizational changes (e.g., restructuring) and labor market developments (e.g., regulations or new job profiles; Cheng \& Chan, 2008; Colakoglu, 2011; De Witte, 1999). This is especially relevant in the context of academic science positions in Germany, because there have been relatively dynamic developments and changes in University structures and job positions in the last years. These developments still hold on with increasing levels of competiveness and expected job and organizational mobility, which makes career insecurity a topic of special relevance for this working population (e.g., Höge et al., 2012).

Another implication of our study is that the positive effects of career adaptability on job and career insecurity are channeled via the same mechanisms, namely internal and external marketability. Against the background of traditional or organizational careers (Schein, 1971), in which careers develop within one organization, internal marketability was negatively related to job and career insecurity. Against the background of new or boundaryless/protean careers (Hall, 2002) in which careers develop across several outside organizations, external marketability was negatively related to job and career insecurity. In the last couple of years, career researchers have treated traditional or organizational careers and new or boundaryless careers more like separated rather than combined models of career development (Eby et al., 2003; Hall, 2002). Although traditional careers have been eroding, not all individual careers develop entirely within new career contexts across the whole life span (Hall, 2002). Also, whereas interorganizational mobility is increasingly likely these days, isolated singular career stages develop within organizations nonetheless. Related to this, Lips-Wiersma and Hall (2007, p. 771) stated that "the pattern of organizational and individual career development actions appear to constitute ... a highly interactive mutual influence process, in which both parties are at once the agent and the target of career influence." Our study took further steps to fill a conceptual research gap by considering variables that are related to both approaches (i.e., traditional careers: internal marketability and job insecurity; new careers: external marketability and career insecurity) in one comprehensive model. This reasoning is further fuelled by the finding that the associations of internal and external marketability and job with regard to career insecurity did not differ in their size.

Besides contributing to research on the intersection between career and organizational research, our study also contributes to existing literature on job and career insecurity. There was a call to study employability-related perceptions as correlates of job insecurity (e.g., Sverke \& Hellgren, 2002). Some researchers already responded to this call and showed, for instance, that perceived external employability is negatively related to job insecurity (De Cuyper et al., 2012). However, it remained unclear whether internal or external employability-related perceptions are equally or differentially relevant to perceptions of insecurity. In our study, we replicated findings by De Cuyper and colleagues (2012), and at the same time extended their findings by showing that perceived internal marketability is as equally important for predicting job insecurity as perceived external marketability. Furthermore, we could show that comparable relations from other studies are also detectable within a highly specified sample of academic researchers in early career stages. This is an indicator that the here found results on less researched model parameters (e.g., external marketability to career insecurity) may also be replicated in working sample from other employment sectors and other educational background.

Finally, career insecurity is a largely understudied but important variable regarding career development and well-being (Colakoglu, 2011; Trevor-Roberts, 2006). Researchers argued that it is distinct but related to job insecurity (Höge et al., 2012). Our study provided two important contributions to this stream of research on career insecurity. First, we showed that career insecurity-operationalized as insecurity about career development and attaining personal career goals — is conceptually different 
from job insecurity and perceived internal and external marketability, as findings of the confirmatory factor analysis showed. Second, although career insecurity is conceptually different from job insecurity, there exist variables that relate to both insecurity variables.

\section{Practical Implications}

We know from earlier research that job insecurity and career insecurity have a negative impact on individuals and organizations (e.g., Cheng \& Chan, 2008; Colakoglu, 2011; Staufenbiel \& König, 2010). Our findings offer direct means to lower such negative effects. Based on our results, we recommend implementing training or coaching interventions that directly focus on fostering individuals' career adaptability. First, research has shown that the ability to adapt to changing career environments can, in fact, be trained. Koen, Klehe, and van Vianen (2012) developed and evaluated successful career adaptability training. Exercises - such as exploring different career interests and options, planning short- and long-term career goals, or even simulated job interview role playing-improved individuals' control and curiosity, which, in turn, enhanced their perceived career adaptability. Such training concepts should be extended within and outside organizational career contexts.

Moreover, our findings suggest that trainings could incorporate components that specifically focus on building individuals' internal and external marketability. For example, trainers or career counselors might analyze their clients' network structures and help them to actively engage in networking behaviors. Visualizing, and ultimately expanding one's career network, might help to include individuals who allow access to new career paths and who might provide potential resources, knowledge, and skills, which may foster one's perceived marketability (e.g., Eby et al., 2003).

These practical recommendations can be helpful for individuals who want to develop within their careers. Moreover, organizations might be interested in implementing training or coaching interventions as outlined previously, as part of their HR strategy, to make sure that their employees feel safe within their current job and career path. As research has shown, job insecurity negatively impacts important variables such as job performance and job satisfaction (Cheng \& Chan, 2008; Huang, Niu, Lee, \& Ashford, 2012) or even absenteeism and turnover intentions (Davy et al., 1997; Staufenbiel \& König, 2010).

\section{Limitations and Future Research}

This study has several strengths, including its longitudinal design with measurements at two points in time. However, as with any empirical investigation, this study also has some limitations. First, the generalizability of our findings needs to be investigated further. We surveyed researchers within early career stages. Future research therefore should explore whether our findings generalize to samples from different educational backgrounds, organizational settings, and career stages. Moreover, it would be interesting to investigate whether the present findings can be substantiated in selfemployed settings as well (especially for career insecurity because it is not related to any specific type of employment). However, we also think that the sample used here is suitable for studying our research questions because in early career stages, challenges and changes that call for career adaptability occur more frequently. Furthermore, as most participants hold a temporary employment contract (with a possibility to be extended), job and career insecurity are prominent topics for the working population analyzed here. This was also reflected in relatively high ratings of job insecurity and career insecurity, which were similar or slightly higher to ratings in previous studies (e.g., Colakoglu, 2011; De Cuyper et al., 2012; Höge et al., 2012; Staufenbiehl \& König, 2010). Thus, even though our sample showed some properties that are special for university researchers, our sample also provides suitable characteristics for studying our research questions. 
Second, our results are based on self-reported data. Thus, we cannot rule out common-method bias (P. M. Podsakoff, MacKenzie, \& Podsakoff, 2012). However, the longitudinal design of our study with two measurement points should have reduced common method bias. Moreover, we separated our study variables by means of confirmatory factor analysis to show that they represent distinct constructs. Nevertheless, causal interpretations of the relations between our study variables are not warranted because it was not an experimental one. Future research should apply different designs that also allow for change analyses and the incorporation of autoregressive effects to approximate to more causal interpretations.

Finally, although we provided initial insight into how career adaptability connects to different insecurity outcomes, more research is needed to explain how adaptability affects career outcomes. This should be done by expanding the nomological network of indirect variables as well as by expanding the type of studied outcome variables. For instance, it might be of interest to explore the mechanisms through which career adaptability is related to well-being or career success.

\section{Conclusion}

This study conceptualized indirect effects of career adaptability on job and career insecurity. By doing so, we showed that perceived internal and external marketability connect career adaptability to job and career insecurity. Results of this study indicate that new career competencies, such as career adaptability, affect multiple insecurity outcomes via multiple mechanisms that should be considered within career and organizational development programs.

\section{Acknowledgments}

The authors would like to thank Nils Christian Sauer and the whole project team for their help in the data collection.

\section{Declaration of Conflicting Interests}

The author(s) declared no potential conflicts of interest with respect to the research, authorship, and/or publication of this article.

\section{Funding}

The author(s) disclosed receipt of the following financial support for the research, authorship, and/or publication of this article: This research was supported by a research grant from the German Ministry of Education and Research (BMBF, Numbers: 01FP1210 and 01FP1209).

\section{References}

Arthur, M. B., \& Rousseau, D. M. (1996). The boundaryless career: A new employment principle for a new organisational era. New York, NY: Oxford University Press.

Baruch, Y., \& Hall, D. T. (2004). The academic career: A model for future careers in other sectors? Journal of Vocational Behavior, 64, 241-262. doi:10.1016/j.jvb.2002.11.002

Becker, G. S. (1993). Human capital: A theoretical and empirical analysis with special reference to education. Chicago, IL: National Bureau of Economic Research, The University of Chicago Press.

Bott, E. M., \& Duffy, R. D. (2015). A two-wave longitudinal study of career calling among undergraduates: Testing for predictors. Journal of Career Assessment, 23, 250-265. doi:10.1177/1069072714535030

Clark, L. A., \& Watson, D. (1995). Construct validity: Basic issues in objective scale development. Psychological Assessment, 7, 309-319. doi:10.1037/1040-3590.7.3.309

Cheng, G., \& Chan, D. (2008). Who suffers more from job insecurity? A meta-analytic review. Applied Psychology, 57, 272-303. doi:10.1111/j.1464-0597.2007.00312.x 
Colakoglu, S. N. (2011). The impact of career boundarylessness on subjective career success: The role of career competencies, career autonomy, and career insecurity. Journal of Vocational Behavior, 79, 47-59. doi:10. 1016/j.jvb.2010.09.011

DeFillippi, R. J., \& Arthur, M. B. (1994). The boundaryless career: A competency-based perspective. Journal of Organizational Behavior, 15, 307-324. doi:10.1002/job.4030150403

de Cuyper, N., Raeder, S., van der Heijden, B. I., \& Wittekind, A. (2012). The association between workers' employability and burnout in a reorganization context: Longitudinal evidence building upon the conservation of resources theory. Journal of Occupational Health Psychology, 17, 162-174. doi:10.1037/ a0027348

de Guzman, A. B., \& Choi, K. O. (2013). The relations of employability skills to career adaptability among technical school students. Journal of Vocational Behavior, 82, 199-207. doi:10.1016/j.jvb. 2013.01.009

Davy, J. A., Kinicki, A. J., \& Scheck, C. L. (1997). A test of job insecurity's direct and mediated effects on withdrawal cognitions. Journal of Organizational Behavior, 18, 323-349. doi:10.1002/(SICI)10991379(199707)18:4<323:: AID-JOB801>3.0.CO;2-\#

Duffy, R. D. (2010). Sense of control and career adaptability among undergraduate students. Journal of Career Assessment, 18, 420-430. doi:10.1177/1069072710374587

Eby, L. T., Butts, M., \& Lockwood, A. (2003). Predictors of success in the era of the boundaryless career. Journal of Organizational Behavior, 24, 689-708. doi:10.1002/job.214

Enders, C. K., \& Bandalos, D. L. (2001). The relative performance of full information maximum likelihood estimation for missing data in structural equation models. Structural Equation Modeling, 8, 430-457. doi:10.1207/S15328007SEM0803_5

Hall, D. T. (2002). Careers in and out of organizations. Thousand Oaks, CA: Sage.

Hirschi, A., \& Herrmann, A. (2012). Vocational identity achievement as a mediator of presence of calling and life satisfaction. Journal of Career Assessment, 20, 309-321. doi:10.1177/1069072711436158

Höge, T., Brucculeri, A., \& Iwanowa, A. N. (2012). Karriereunsicherheit, Zielkonflikte und Wohlbefinden bei Nachwuchswissenschaftlerinnen und -wissenschaftlern [Career insecurity, goal conflicts, and well-being among young scientists: A study in three countries]. Zeitschrift für Arbeits- und Organisationspsychologie, 56, 159-172. doi:10.1026/0932-4089/a000088

Huang, G. H., Niu, X., Lee, C., \& Ashford, S. J. (2012). Differentiating cognitive and affective job insecurity: Antecedents and outcomes. Journal of Organizational Behavior, 33, 752-769. doi:10.1002/job.1815

Keim, A. C., Landis, R. S., Pierce, C. A., \& Earnest, D. A. (2014). Why do employees worry about their jobs? A meta-analytic review of predictors of job insecurity. Journal of Occupational Health Psychology, 10, 269-290. doi:10.1037/a0036743

Kline, R. B. (2005). Principles and practice of structural equation modeling. New York, NY: The Guilford Press.

Koen, J., Klehe, U.-C., \& van Vianen, A. E. M. (2012). Training career adaptability to facilitate a successful school-to-work transition. Journal of Vocational Behavior, 81, 395-408. doi:10.1016/j.jvb. 2012.10.003

König, C. J., Debus, M. E., Häusler, S., Lendenmann, N., \& Kleinmann, M. (2010). Examining occupational self-efficacy, work locus of control and communication as moderators of the job insecurityjob performance relationship. Economic and Industrial Democracy, 31, 231-247. doi:10.1177/ 0143831 X09358629

Lips-Wiersma, M., \& Hall, D. T. (2007). Organizational career development is not dead: A case study on managing the new career during organizational change. Journal of Organizational Behavior, 28, 771-792. doi:10.1002/job.446

Maggiori, C., Johnston, C., Krings, F., Massoudi, K., \& Rossier, J. (2013). The role of career adaptability and work conditions on general and professional well-being. Journal of Vocational Behavior, 83, 437-449. doi:10.1016/j.jvb.2013.07.001 
Mauno, S., Leskinen, E., \& Kinnunen, U. (2001). Multi-wave, multi-variable models of job insecurity: Applying different scales in studying the stability of job insecurity. Journal of Organizational Behavior, 22, 919-937. doi:10.1002/job.122

Muthén, L. K., \& Muthén, B. O. (1998-2012). Mplus user's guide (7th ed). Los Angeles, CA: Muthén \& Muthén.

Nota, L., Ginevra, M. C., \& Soresi, S. (2012). The career and work adaptability questionnaire (CWAQ): A first contribution to its validation. Journal of Adolescence, 35, 1557-1569. doi:10.1016/j.adolescence. 2012.06.004

Parker, P., \& Arthur, M. B. (2002). Bringing "new science" into careers research. Management, 5, 105-125. doi:10.3917/mana.051.0105

Podsakoff, P. M., MacKenzie, S. B., \& Podsakoff, N. P. (2012). Sources of method bias in social science research and recommendations on how to control it. Annual Review of Psychology, 65, 539-569. doi:10. 1146/annurev-psych-120710-100452

Preacher, K. J., \& Hayes, A. F. (2008). Asymptotic and resampling strategies for assessing and comparing indirect effects in multiple mediator models. Behavior Research Methods, 40, 879-891. doi:10.3758/BRM.40.3. 879

Rosenblatt, Z., \& Ruvio, A. (1996). A test of a multidimensional model of job insecurity: The case of Israeli teachers. Journal of Organizational Behavior, 17, 587-605. doi:10.1002/(SICI)1099-1379(199612)17: $1+<587::$ AID-JOB825>3.0.CO;2-S

Rottinghaus, P. J., Day, S. X., \& Borgen, F. H. (2005). The career futures inventory: A measure of careerrelated adaptability and optimism. Journal of Career Assessment, 13, 3-24. doi:10.1177/ 1069072704270271

Savickas, M. L., \& Porfeli, E. J. (2012). Career adapt-abilities scale: Construction, reliability, and measurement equivalence across 13 countries. Journal of Vocational Behavior, 80, 661-673. doi:10.1016/j.jvb. 2012.01.011

Schein, E. H. (1971). The individual, the organization, and the career: A conceptual scheme. Journal of Applied Behavioral Science, 4, 401-426. doi:10.1177/002188637100700401

Soresi, S., Nota, L., \& Ferrari, L. (2012). Career adapt-abilities scale-Italian form: Psychometric properties and relationships to breadth of interests, quality of life, and perceived barriers. Journal of Vocational Behavior, 80, 705-711. doi:10.1016/j.jvb.2012.01.020

Spurk, D., Kauffeld, S., Barthauer, L., \& Heinemann, N. S. R. (2015). Fostering networking behavior, career planning and optimism, and subjective career success: An intervention study. Journal of Vocational Behavior, 87, 134-144. doi:10.1016/j.jvb.2014.12.007

Spurk, D., \& Volmer, J. (2013). Validierung einer deutschen version des Career Futures Inventory (CFI): Berufliche Anpassungsfähigkeit, beruflicher Optimismus, Arbeitsmarktwissen und Berufserfolg [Validation of a German version of the Career Futures Inventory (CFI): Career adaptability, career optimism, job market knowledge, and career success]. Zeitschrift für Arbeits- und Organisationspsychologie, 57, 77-95. doi:10.1026/0932-4089/a000106

Spurk, D., Volmer, J., Hagmaier, T., \& Kauffeld, S. (2013). Why are proactive people more successful in their careers? The role of career adaptability in explaining multiple career success criteria. In E. E. Crossman \& M. A. Weiler (Eds.), Personality traits: Causes, conceptualizations, and consequences (pp. 27-48). New York, NY: Nova Publishers.

Staufenbiel, T., \& König, C. J. (2010). A model for the effects of job insecurity on performance, turnover intention, and absenteeism. Journal of Occupational and Organizational Psychology, 83, 101-117. doi:10.1348/ $096317908 X 401912$

Super, D. E., \& Kidd, J. M. (1979). Vocational maturity in adulthood: Toward turning a model into a measure. Journal of Vocational Behavior, 14, 255-270. doi:10.1016/0001-8791(79)90054-X

Super, D. E., \& Knasel, E. G. (1979). Specifications for a measure of career adaptability in young adults. Cambridge, England: National Institute for Career Education and Counseling. 
Sverke, M., \& Hellgren, J. (2002). The nature of job insecurity: Understanding employment uncertainty on the brink of a new millennium. Applied Psychology: An International Review, 51, 23-42. doi:10.1111/1464$0597.0077 \mathrm{z}$

Trevor-Roberts, E. (2006). Are you sure? The role of uncertainty in careers. Journal of Employment Counselling, 43, 98-113. doi:10.1002/j.2161-1920.2006.tb00010.x

De Witte, H. D. (1999). Job insecurity and psychological well-being: Review of the literature and exploration of some unresolved issues. European Journal of Work and Organizational Psychology, 8, 155-177. doi:10.1080/135943299398302

Wittekind, A., Raeder, S., \& Grote, G. (2010). A longitudinal study of determinants of perceived employability. Journal of Organizational Behavior, 31, 66-586. doi:10.1002/job.646

Wolff, H. -G., \& Moser, K. (2009). Effects of networking on career success: A longitudinal study. Journal of Applied Psychology, 94, 196-206. doi:10.1037/a0013350 